
Кудря Александр Дмитриевич

\title{
ФИЗКУЛЬТУРНО-СПОРТИВНАЯ ДЕЯТЕЛЬНОСТЬ КАК ФАКТОР СОЦИАЛИЗАЦИИ СТУДЕНТОВ В СИСТЕМЕ ВЫСШЕГО ПРОФЕССИОНАЛЬНОГО ОБРАЗОВАНИЯ
}

Статья посвяцена исследованию физкультурно-спортивной деятельности в системе высшего профессионального образования, которая выступает ведуцим фактором сочиилизации студентов и помогает им вне учебного времени формировать и пропагандировать культуру здорового образа и стиля жизни, учиться прилагать собственные усилия в сохранение и улучиение здоровья, достижение жизненных и учебных целей. Физкультурно-спортивная деятельность непосредственно участвует в формировании личности студента, и при этом создается достаточная мотивауия их к физическому самовоспитанию и самосовериенствованио.

Ключевые слова: физкультурно-спортивная деятельность, система высшего профессионального образования, фактор сочиализации студентов, здоровье, здоровый образ жизни, физическое самовоспитание и самосовериенствование.

\section{Oleg Borisov, Khasan Arov, Olga Tsybulenko, Dmitry Gladkikh, Alexander Kudrya \\ PHYSICAL CULTURE AND SPORTS ACTIVITIES AS A FACTOR \\ IN THE SOCIALIZATION OF STUDENTS IN THE SYSTEM OF HIGHER PROFESSIONAL EDUCATION}

The article is devoted to the study of physical culture and sports activities in the system of higher professional education, which is a leading factor in the socialization of students and helps them to form and promote a healthy lifestyle and lifestyle culture outside of school hours, learn to make their own efforts to maintain and improve health, achieve life and training goals. Physical culture and sports activities are directly involved in the formation of the student's personality and at the same time sufficient motivation is created for them to physical self-education and self-improvement.

Key words: Physical culture and sports activities, the system of higher professional education, the factor of socialization of students, health, healthy lifestyle, physical self-education and self-improvement.

Bведение / Introduction. В современном мире за счет активного развития науки и техники происходят постоянные изменения в сфере производства, экономики и политики, а также миграция населения, быстрая смена информационных потоков. Это способствует формированию новых профессиональных требований к профилю и качеству подготовки специалистов в системе высшего профессионального образования [4]

Для профессионального роста специалиста, а также студента как будущего специалиста. наряду с глубокими знаниями становятся значимыми такие качества, как умение:

- адаптироваться к меняющимся социально-экономическим условиям;

- $\quad$ работать в сотрудничестве с людьми, относящимся к различным социально-культурным и профессиональным группам;

- принимать самостоятельные решения. 
Mатериалы и методы / Materials and methods. Возвращение современного общества к пониманию известных в цивилизованном мире истин о значительной ценности здоровья и здорового образа жизни поставило перед преподавателями высшей школы серьезные задачи по оздоровлению студенческой молодежи.

Для их решения требуется усовершенствование:

- материально-технической базы;

- методического и научно-организационного обеспечения учебного процесса.

Уровень здоровья и работоспособность современного специалиста и студента должны быть достаточными для того, чтобы быть динамичными и готовыми к профессиональному росту в течение многих лет. Сохранению здоровья студентов и развитию вышеназванных умений в значительной мере способствует физкультурно-спортивная деятельность, которая организуется кафедрами физической культуры высших учебных заведений страны. В социально-психологическом аспекте студенчество, по сравнению с другими группами населения, отличается более высоким образовательным уровнем и высоким уровнем познавательной мотивации.

Изучение психофизиологического состояния студентов, проведенное рядом исследователей, показало, что студенческой молодежи, наряду с высоким уровнем развития интеллектуальных способностей, свойственны:

- фрустрированность;

- озабоченность планами:

- $\quad$ напряженная раздражимость;

- частая смена настроения;

- склонность к общему социальному торможению [2].

Способность молодого человека к сознательной регуляции своего поведения в 17-19 лет развита еще не в полной мере. Студенческий возраст характеризуется как концептуальная социализация, когда формируются устойчивые свойства личности и сознательные мотивы поведения.

Обучение профессии в высшем учебном заведении выступает как основной и непосредственный носитель механизмов социальных отношений для студентов, позволяет им не только приобрести профессионально-трудовые умения и навыки, но и получить представление о характере взаимоотношений между людьми. Молодые люди желают найти свое место в обществе, их социализация находится в стадии интеграции. Интеграция происходит благополучно, если личностные качества человека принимаются группой, обществом. Но в то же время социализация не всегда бывает успешной.

Результаты и обсужсдение / Results and discussion. Согласно ряду исследований, от 43 до $48 \%$ юношей и девушек студенческого возраста имеют трудности поведенческого характера $[1,3,4]$.

Физкультурная деятельность и спорт в высших учебных заведениях страны помогают молодым людям преодолеть последствия отклоняющейся социализации и облегчают процесс их интеграции в общество, так как приобщают человека к ценностям гуманизма, нормам и моделям поведения, приближенным к идеалу.

Физкультурное образование - это более глубокое освоение достижений физической культуры.

Физическая культура является компонентом профессиональной подготовки студента. Каждому студенту вуза необходимо овладеть теорией и методикой физического воспитания [5].

В формировании социализации личности студента важное место в учебном процессе вузов уделяется теоретическим занятиям по основам здорового образа жизни, которые занимают до 30 $\%$ программных часов по физической культуре.

На таких занятиях разбираются вопросы:

- организации самостоятельных занятий и самоконтроля;

- воспитания необходимых физических качеств у занимающихся физической культурой студентов;

- изучение методики составления комплексов утренней гигиенической гимнастики [2] 
Большое значение в формировании физической культуры студенческой молодежи имеет внеучебная физкультурно-оздоровительная деятельность, которая организуется кафедрами физической культуры университета.

Так в Северо-Кавказском федеральном университете разработана и действует в течение многих лет система внеучебной спортивно-массовой работы, которая позволяет привлекать студенческую молодежь к активным занятиям физической культурой и спортом на протяжении всего периода обучения в вузе.

В течение учебного года в университете между институтами проводятся студенческие спартакиады по следующим видам спорта: легкой атлетике; легкоатлетическому кроссу; плаванию; аэробике; шахматам; баскетболу; волейболу; настольному теннису; футболу; дартсу; гимнастике.

Перечисленные виды спорта пользуются наибольшей популярностью среди студентов. В студенческой спартакиаде принимают участие сборные команды всех институтов Северо-Кавказского федерального университета.

Для того чтобы сформировать сборные команды по видам спорта, в институтах проводятся соревнования между группами, курсами; товарищеские встречи со студенческими командами других институтов; товарищеские встречи с командами преподавателей университета; дополнительные учебно-тренировочные занятия в воскресные дни.

Такую работу совместно со студенческим активом проводит заместитель директора института по спортивно-массовой работе.

В каждой команде института по виду спорта выбран капитан, который участвует в комплектовании команды и ее управлении.

Несколько раз в год собирается совет капитанов, который рассматривает вопросы:

- планирования спортивно-массовой работы;

- $\quad$ летнего отдыха спортсменов и их поощрения спортивной формы;

- анализа результатов выступлений студентов на соревнованиях.

В работе совета капитанов принимают участие: директор института; заместитель директора института по учебные работы; заместитель директора института по спортивно-массовой работе.

Сотрудничество студентов и преподавателей институтов в организации внеучебной деятельности и досуга студентов является успешным.

В течение последних пяти лет в соревнованиях различного уровня ежегодно принимали участие 45-50\% человек. Активное участие студентов в организации и проведении оздоровительных и спортивных мероприятий способствует тому, что их социализация происходит более благополучно.

Более $65-70 \%$ спортсменов институтов учатся на «хорошо» и «отлично», принимают активное участие в общественной и научной деятельности.

Важность реализации этого обучения в том, что задачей преподавателей является обучение студентов правилам ведения здорового образа жизни, ничем не заменимым, в содержание которого входят физическая культура и спорт [1].

Заключение/Conclusion. Исходя из вышеизложенного мы можем констатировать тот факт, что физкультурно-спортивная деятельность, выступающая фактором социализации студентов в системе высшего профессионального образования во внеучебное время помогает студентам:

- формировать и пропагандировать культуру здорового образа и стиля жизни;

- $\quad$ научиться прилагать собственные усилия в сохранении и улучшении здоровья, достижении жизненных и учебных целей;

- $\quad$ формировать личность и при этом создавать достаточную мотивацию к физическому самовоспитанию и самосовершенствованию [1]. 


\section{ЛИТЕРАТУРА И ИНТЕРНЕТ-РЕСУРСЫ}

1. Выдрин, В. М. Спорт в современном обществе / В. М. Выдрин. - Москва : Физкультура и спорт, 2014. - 288 с. - Текст : непосредственный.

2. Лисовский, В. Т. и др. Социология молодежи : учеб̆ник. / В. Т. Лисовский. - Санкт-Петербург : Издво Санкт-Петербургского университета, 1996. - 460 с. - Текст : непосредственный.

3. Лубышева, Л. И. Социология физической культуры и спорта: учеб. пособие / Л. И. Лубышева. - Москва : Академия, 2012. - 240 с. - Текст : непосредственный.

4. Пономарев, Н. А. Социология физической культуры: учебное пособие / Н. А. Пономарев; ГАФК им. П. Ф. Лесгафта. - Санкт-Петербург, 2010. - 118 с. - Текст : непосредственный.

5. Соловьев, Г. М. Физическое воспитание и образование в вузах : учеб. пособие / Г. М. Соловьев. Ставрополь : СГПИ, 1993. - 86 с. - Текст : непосредственный.

\section{REFERENCES AND INTERNET RESOURCES}

1. Vydrin, V. M. Sport v sovremennom obshchestve (Sport in modern society) / V. M. Vydrin. - Moskva : Fizkul'tura i sport, 2014. $-288 \mathrm{~s}$.

2. Lisovskii, V. T. i dr. Sotsiologiya molodezhi (Sociology of youth): uchebnik / V. T. Lisovskii. - SanktPeterburg : Izd-vo Sankt-Peterburgskogo universiteta, 1996. - $460 \mathrm{~s}$.

3. Lubysheva? L. I. Sotsiologiya fizicheskoi kul'tury i sporta (Sociology of physical culture and sports): ucheb. posobie / L. I. Lubysheva. - Moskva : Akademiya, 2012. - 240 s.

4. Ponomarev, H. A. Sotsiologiya fizicheskoi kul'tury (Sociology of physical education) : uchebnoe posobie / H. A. Ponomarev; GAFK im. P. F. Lesgafta. - Sankt-Peterburg, 2010. - $118 \mathrm{~s}$.

5. Solov'ev G. M. Fizicheskoe vospitanie i obrazovanie v vuzakh (Physical education and education in universities): ucheb. posobie / G. M. Solov'ev. - Stavropol' : SGPI, 1993. - 86 s.

\section{СВЕДЕНИЯ ОБ АВТОРАХ}

Борисов Олег Юрьевиџ, старший преподаватель, кафедры физической подготовки и спорта, Ставропольского филиала Краснодарского Университета МВД России. E-mail: kudrya.sasha70@mail.ru

Аров Хасаи Нанурович, кандидат биологических наук, доцент, кафедры социально-гуманитарных и юридических наук. Невинномысского Государственного Гуманитарно-Технического института. E-mail: kudrya.sasha70@mail.ru

Цыбуленко Ольга Петровна, кандидат психологических наук, доцент кафедры психологии, образования и педагогических наук, Невинномысского Государственного Гуманитарно-Технического института. E-mail: kudrya.sasha70@mail.ru

Гладких Дмитрий Геннадьевич, кандидат педагогических наук, доцент, заведующий кафедрой физического воспитания и спорта, Ставропольского Государственного Аграрного университета E-mail: kudrya. sasha70@mail.ru

Кудря Александр Дмитриевич, кандидат педагогических наук, преподаватель ЧПОУ МК «Авиценна» Г. Ставрополь. E-mail: kudrya.sasha70@mail.ru

\section{INFORMATION ABOUT AUTHORS}

Oleg Borisov, Senior Lecturer, Department of Physical Training and Sports, Stavropol Branch of the Krasnodar University of the Ministry of Internal Affairs of Russia. E-mail: kudrya.sasha70@mail.ru

Hasan Arov, candidate of biological sciences, associate professor, department of social, humanitarian and legal sciences. Nevinnomyssk State Humanitarian Technical Institute. E-mail: kudrya.sasha70@mail.ru

Olga Tsybulenko, candidate of psychological sciences, associate professor of the department of psychology, education and pedagogical sciences, Nevinnomyssk State Humanitarian-Technical Institute. E-mail: kudrya.sasha70@mail.ru

Dmitry Gladkikh, Candidate of Pedagogical Sciences, Associate Professor, Head of the Department of Physical Education and Sports, Stavropol State Agrarian University. E-mail: kudrya.sasha70@mail.ru

Aleksandr Kudrya, candidate of pedagogical sciences, lecturer of MK "Avicenna", Stavropol. E-mail: kudrya. sasha70@mail.ru 